\title{
Dimensões Constitutivas de Tecnologias Sociais no Campo da Saúde: uma proposta de construção e apropriação de conhecimento em territórios vulneráveis
}

\author{
Constitutive Dimensions of Health Field's Social Technologies: a proposal for construction and
} appropriation of knowledge in critically vulnerable territories

CRISTINA MARIA BARROS DE MEDEIROS*

LUIZA ROSANGELA DA SILVA**

8003

\begin{abstract}
RESUMO - Ao longo dos últimos quinze anos, o conceito de tecnologia social (TS) vem incorporando diversos significados e usos, o que revela a necessidade de diferentes metodologias para sua aplicação e seu entendimento, conforme o campo disciplinar e o objeto. Em saúde coletiva, o termo guarda interface com a noção de determinantes sociais em saúde (DSS), dada a heterogeneidade de demandas geradas sobre o sistema de saúde pelos mais variados contextos culturais, ambientais e socioeconômicos. Enseja, portanto, a construção e investigação de processos, de práticas, de fluxos de comunicação e informação entre atores e territórios diversos - enfim, dimensões específicas do que é definido como tecnologia social em saúde (TSS). Este artigo sistematiza, pela primeira vez, a metodologia utilizada para a emersão de um conceito multidimensional e coletivamente construído de TSS, a partir de uma iniciativa realizada pela Fundação Oswaldo Cruz em 2009, em um território de alta vulnerabilidade social no Rio de Janeiro, adotada, desde então. Finalmente, sublinha a capacidade de adequação desta metodologia para abordar as complexas questões impostas por estes territórios.
\end{abstract}

Palavras-chave - Tecnologias Sociais em Saúde. Determinantes sociais da saúde. Saúde coletiva. Políticas públicas multissetoriais. Controle social.

ABSTRACT - Over the last fifteen years, the concept of social technology (TS) has been incorporating different meanings and uses, revealing the need for different methodologies for its application and understanding, depending on the disciplinary field and the object. In public health, the term guards an interface with the notion of social determinants of health (SDH), given the heterogeneity of demands generated on the health care system for all kinds of cultural, environmental and socioeconomic contexts. This therefore entails the construction and investigation of various processes and practices, as well as communication and information flows between actors and different territories - in short, specific dimensions of what we define as health social technology (TSS). This article explains, for the first time, the methodology used to provoke the emergence of a collectively constructed multidimensional concept of TSS, from an initiative carried out by the Oswaldo Cruz Foundation in an area of critical social vulnerability, in Rio de Janeiro, in 2009, adopted since then. Finally, it underlines the adaptability of this approach to address the complex issues these territories impose.

Keywords - Social Technologies in Health. Social determinants of health. Collective health. Multi-sector public policies. Social control.

* Doutora em Engenharia de Produção pela Universidade Federal do Rio de Janeiro (UFRJ). Chefe do Laboratório de Iniciação Científica na Educação Básica (Lic-Provoc) da Escola Politécnica de Saúde Joaquim Venâncio/Fundação Oswaldo Cruz, Rio de Janeiro - RJ/Brasil. CV: http://lattes.cnpq.br/5168223486733585. E-mail: cristinabarros@fiocruz.br.

** Doutora em Engenharia de Produção pela Universidade Federal do Rio de Janeiro (UFRJ); Coordenadora do Registro Brasileiro de Ensaios Clínicos/Instituto de Comunicação e Informação Científica e Tecnológica em Saúde/ Fundação Oswaldo Cruz, Rio de Janeiro - RJ/Brasil. CV: http://lattes.cnpq.br/1815186357925362.E-mail: luiza.silva@icict.fiocruz.br.

Submetido em: novembro/2015. Aprovado em: maio/2016. 
á territórios que conjugam ambiente marcado por baixos índices de saúde ambiental alagamentos/enchentes, poluição dos rios, ineficiente coleta de resíduos, convívio com diversos vetores de doenças, entre outros fatores - e elevada dificuldade de mobilidade e acessibilidade para pessoas portadoras de necessidades especiais, devido, principalmente, às irregularidades das vias mínimas de acesso. Nestes lugares, a pobreza serve de combustível a um círculo vicioso que inclui não só o adoecimento dos corpos, mas também do tecido social: a população residente lida com condições precárias no entorno de suas casas e tende a envelhecer mais cedo, posto que adoece mais constantemente.

O coletivo de cidadãos moradores pobres e à margem da cidadania, suas relações entre si e com o lugar - mas também com lugares e cidadãos de fora desse círculo - constituem e, ao mesmo tempo, habitam esses cenários marcados pela desigualdade, plasmando, historicamente, uma cultura de cisão da cidadania.

O conhecimento sobre tais fenômenos vem sendo construído por meio de pesquisas e livros de abordagens variadas: planejamento urbano e arquitetura, sociologia, antropologia, serviço social, segurança e saúde pública, entre outras áreas. Não obstante, as situações são recorrentes e perceptíveis empiricamente, ao percorrermos as metrópoles brasileiras. No caso do Rio de Janeiro, há, no entanto, certas peculiaridades: esses territórios são interfaceados por bairros de alto padrão socioeconômico, o que leva enormes contingentes populacionais residentes em ambos os tipos de territórios a conviver com uma disparidade de infraestrutura e de serviços básicos tão flagrante quanto inconciliável.

Uma das regiões emblemáticas desta situação, o Complexo de Manguinhos, constituído por quatorze comunidades, é um microcosmo de desigualdade ora amenizada, ora ressaltada pela presença e pela evasão de grandes empresas públicas e privadas ${ }^{1}$. A combinação de restrições materiais essenciais, sobreposição de ações/projetos pontuais do poder público com políticas sociais, estimulando o assistencialismo e o paternalismo, tem marcado diretamente a história recente nas últimas três décadas das comunidades que o integram.

A complexidade das questões impostas por tais territórios exige enfrentamento por meio de propostas de políticas multissetoriais e ações interdisciplinares, entre as quais inserem-se os conceitos de Tecnologias Sociais e de Determinantes Sociais da Saúde (DSS), cujo alinhamento dá origem a outro: Tecnologias Sociais em Saúde (TSS). Esse trabalho apresenta uma experiência de construção conceitual de Tecnologias Sociais em Saúde, a partir de dimensões identificadas como estruturantes, durante um movimento pioneiro de apoio a projetos integrando tecnologias sociais e saúde em contextos de vulnerabilidade social. Patrocinada pela Fiocruz, mas concebida e desenvolvida em co-construção com atores sociais - por meio de ações e discussões com foco na sustentabilidade em curto, médio e longo prazos -, a experiência fez emergir uma metodologia adaptável para planejamento e uso em projetos cuja meta seja a geração de capacidades para a transformação social, fundada no engajamento crítico e na participação.

\section{Da técnica às tecnologias sociais}

Tecnologia, a partir de seus componentes etimológicos, significa estudo da arte, da técnica ou do ofício, logo: estudo da técnica em suas múltiplas interfaces e relações (MEDEIROS, 2010). Portanto, não há como falar de tecnologia sem mencionar a técnica. A história da técnica é a história de duas grandes transformações que se influenciam mutuamente: uma, envolvendo os artefatos; outra, a estrutura das organizações sociais humanas. Independentemente das dimensões, categorias ou visões sobre a técnica, a 
partir da reflexão sobre o seu fazer e refazer, a humanidade avançou criticamente em relação a conceitos e práticas, aprimorando seu entendimento sobre seu modo de estar no mundo.

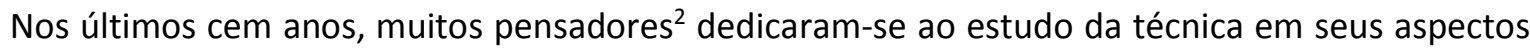
histórico, sociológico e filosófico, envolvendo diferentes áreas do conhecimento sobre suas origens, meios e fins. A invenção, seus processos e resultados passaram a ser objeto de análise segundo diferentes pontos de vista. Dependendo do momento histórico e cultura em que estavam inseridos, estudiosos propuseram teorias, categorias e fases de desenvolvimento, desdobrando consensos e dissensos.

Para Leontiev (1972), pela técnica, o homem se relaciona com a natureza no convívio com outros homens, sendo as ações humanas interdependentes. O construto e uso de instrumentos, além da realização de atividades comuns, em cooperação, favoreceram as conquistas e descobertas em prol de coletividades. Ao mesmo tempo em que a técnica desenvolveu novos modos de estar no mundo, ela mudou o homem. Este, consolidando suas necessidades de descobrir, desbravar e inventar percebeu que a técnica poderia ser utilizada junto a/em conjunto com outros homens para atingir objetivos comuns.

Baumgarten (2002, p. 31) afirma que a história da ciência "encontra-se profundamente imbricada" não só com a perspectiva humana sobre a natureza, mas também com as formas assumidas pelas relações entre os homens e deles com a natureza na produção de sua vida. Esse imbricamento está refletido nas relações e vínculos em sociedade - desde a divisão fortuita das atividades técnicas nos primórdios da cultura humana, até as complexas divisões das tarefas e atividades do trabalho presentes nos processos de produção modernos - promoveu o desenvolvimento, o domínio e o aperfeiçoamento da técnica humana (MEDEIROS, 2010). Há quem compreenda a tecnologia como uma parte mesma do conhecimento humano, voltada para a criação e uso de meios técnicos e suas inter-relações com a vida - a sociedade e seu entorno. Necessário, portanto, considerar em seu arcabouço:

(...) possuir relação com a ciência, com a técnica e com a sociedade; integrar elementos materiais - ferramentas, máquinas, equipamentos - e não materiais saber fazer, conhecimentos, informações, organização, comunicação e relações interpessoais; ter relações com fatores econômicos, políticos e culturais; e o fato de que a tecnologia é inseparável das estruturas sociais de uma determinada sociedade (BAZZO, 1998, p. 153).

O caráter plástico da tecnologia - e não a sua suposta neutralidade - instiga o homem a pensar sobre o seu sentido, uso e natureza. O progresso da técnica passou a ser associado ao progresso social e à ideia de desenvolvimento. Rapidamente, a divisão nas categorias desenvolvido/subdesenvolvido marcou um mundo cada vez mais preocupado com diferenciais que correspondessem a esse tipo de destaque no cenário mundial. Estudiosos - interessados na evolução dos aparatos tradicionais aos sofisticados sistemas tecnológicos que acenavam com um futuro promissor para os povos - erigiram paulatinamente a crítica a essa associação, ao constatarem que este processo deu origem a novos fenômenos de controversos impactos sociais e ambientais.

Tais fenômenos poderiam ser claramente vinculados a índices de desenvolvimento propostos a partir da capacidade tecnológica instalada, e caracterizados como questões estruturais, uma vez que davam, por si, origem a novas realidades sociais: desemprego e suas consequências são exemplo. Na prática, puderam ser identificados vários tipos de oposição, nascidos da mesma matriz associando capital e tecnologia: consumidores e não-consumidores, incluídos e excluídos, ricos e pobres (DAGNINO et al, 2004).

A partir da primeira metade do Século XX, não tardaram movimentos no sentido de possibilitar o crescimento econômico com desenvolvimento social, mas ainda longe de oferecer autonomia processual aos sujeitos envolvidos. O que se difundiu nessa fase, primeiramente, nasceu em oposição às tecnologias convencionais, aliadas das grandes corporações capitalistas. As tecnologias apropriadas e suas diferentes denominações defendiam uma política científica e tecnológica não usurpadora do capital humano na sua 
implementação. Não se configurava um retorno às técnicas tradicionais, mas preconizava-se um melhoramento e adaptação de condições locais de produção, com vistas à resolução de problemas específicos (NOVAES; DIAS, 2010).

Esse primeiro movimento foi aplicado em alguns planos latino-americanos para geração de postos de trabalho pela possibilidade de menor investimento, sobretudo em setores produtores de bens básicos, colocando-se como alternativa ao modelo capitalista hegemônico. Ainda na década de 1970, surgiram críticas ao modelo tecnológico de apropriação por consistir em intervenções paliativas, destinadas a usuários de reduzida escolaridade, caracterizando-se, em dadas circunstâncias, como políticas paternalistas.

Somente a partir do ano 2000 o conceito e a prática de Tecnologia Social (TS) foram pautados no Brasil (DAGNINO et al, 2004) por diversas instituições (universidades, institutos e grupos de pesquisa, ONGs, esferas de governo), na tentativa de desenvolver outro modelo de tecnologia que levasse em consideração a participação popular e a inclusão social. Focaliza-se o binômio problema-solução como um processo de co-construção coletiva. Consiste, pois, numa visão sistêmica acerca de situações-contexto que longe estão de resolução pontual (THOMAS, 2011). Baumgarten (2002) aponta, entre as condições críticas para que o Brasil possa construir um desenvolvimento "baseado na sustentabilidade humana, solidária com a biosfera e com as gerações futuras".

(...) [A] integração e compatibilização com políticas de C\&T e políticas econômicas e educacionais, bem como as ações entre níveis federal, estadual e municipal; encaminhar a questão das desigualdades regionais e das potencialidades e capacidades dos sistemas locais de conhecimento, buscando qualificá-los tendo em vista sua proximidade e maior identificação com as necessidades locais (BAUMGARTEN, 2002, p. 40).

\section{DSS, TSS e aproximações com o Serviço Social}

Para este artigo, tecnologias sociais são entendidas como um modelo que combina estratégias, processos e produtos construídos de modo compartilhado, com foco na mudança das dinâmicas de inclusão social e em políticas públicas, visando ao desenvolvimento mais equitativo. Não são poucas, portanto, as interseções entre esse conceito e o campo do Serviço Social ${ }^{3}$, posto que o conhecimento gerado pela TS e os seus resultados são voltados para o desenvolvimento social; a tecnologia media a garantia e o exercício dos direitos sociais, não da oferta para o mercado:

As iniciativas de TS se constituem em uma das mais profícuas alternativas de enfrentamento das expressões da questão social, por se tratar de experiências constituídas por meio das iniciativas comunitárias locais, pelo saber popular em articulação com os saberes acadêmicos, por processos participativos e democráticos (...). Além disso, são reveladoras da capacidade da sociedade em se organizar em função dos interesses da comunidade, partindo, muitas vezes, da identificação do capital já existente na comunidade e que passa a ser potencializado para benefício da coletividade. Em alguns casos, esse processo de organização vem acompanhado do trabalho, em parceria, de técnicos e pesquisadores, mas é importante destacar que esse acompanhamento não é uma condição sine qua non para que se constituam as TS. (MACIEL; FERNANDES, 2011, p. 162-163). 
O que se convencionou chamar de Tecnologias Sociais no campo da Saúde (TSS) se constrói a partir de pesquisas aplicadas aos temas prioritários para os territórios - definidos participativamente -, com condições sustentáveis para o desenvolvimento de técnicas, métodos e processos inovadores. Inovação, neste caso, envolve aproximação, comprometimento e co-construção de pesquisas científicas pela estruturação e modelagem de tecnologias em saúde, efetivamente direcionadas para a redução de iniquidades gerais e específicas dos territórios.

Esta formulação tem raízes comuns com a Epidemiologia Crítica, escola e movimento criados com a contribuição de pesquisadores latino-americanos, como Jaime Breilh e Sérgio Arouca, naquele contexto crítico da década de 1970 a que nos referimos; sua abordagem orienta-se a compreender a saúde por sua dimensão positiva, assumindo que as concepções do processo de saúde e doença não poderiam se restringir aos esquemas causais de produção do agravo.

O Movimento da Reforma Sanitária teve, nesse período, um papel marcante no que se refere ao processo de discussão e reflexão do conceito ampliado de saúde, da proposição de um novo modelo assistencial de saúde orientado para a promoção da saúde e prevenção da doença com a participação popular (MOTTER; ALVES, 2006, p. 153) ${ }^{4}$.

Tal visão avança pelos anos 1980 como parte da oposição a diretrizes entendidas como neoliberais, expressas por ações concretas, diretamente danosas aos direitos coletivos (PASTOR, 2007); sustenta que problemas de saúde coletiva não podem ser descolados do processo histórico que os determina - portanto, não podem ser explicados nem enfrentados apenas com a ótica e o instrumental próprios do binômio médico-tecnológico.

A natureza social da doença não se verifica no caso clínico, mas no modo característico de adoecer e morrer nos grupos humanos. Ainda que provavelmente a "história natural" da tuberculose, por exemplo, seja diferente, hoje, do que era há cem anos, não é nos estudos dos tuberculosos que vamos apreender melhor o caráter social da doença, porém nos perfis patológicos que os grupos sociais apresentem (LAURELL, 1983, p. 3).

Por essa via, percebemos que há implicação do pensamento social sobre entendimento dos processos saúde-doença, e que a consideração do enfrentamento das questões que levanta por meio do entendimento da dinâmica de grupos - e não de indivíduos -, tanto quanto do natural como histórico, indica a relação daqueles com o seu ambiente e com uma cultura dada por essa relação. O próprio conceito de saúde, portanto, é ampliado: "não envolve apenas o tratamento e recuperação da doença, mas a articulação entre os setores social e econômico" (MOTTER; ALVES, 2006). E, uma vez que as tecnologias convencionais guardam correspondência com a lógica capitalista - e não apenas em função de sua intensividade de investimento - são determinadas antes pela conveniência econômica de parcela restrita do mercado que pelo interesse dos cidadãos e das coletividades.

Essa leitura permite o surgimento da categoria Determinação Social da Saúde (DSS), expressão de uma visão positiva e ampliada da saúde que influenciou e foi influenciada por movimentos sociais e populações vulnerabilizadas, inscritos na luta por transformações estruturais nos modos de produção da vida (BREILH, 2006; 2011). No Brasil, a Reforma Sanitária, a constituição do SUS e de seus princípios estruturadores, por exemplo, são expressões históricas deste ideário, cujo modelo ${ }^{5}$ interpretativo mais amplamente difundido na comunidade científica foi desenvolvido por Dahlgren e Whitehead (1991), como apresentado na Figura 1. 


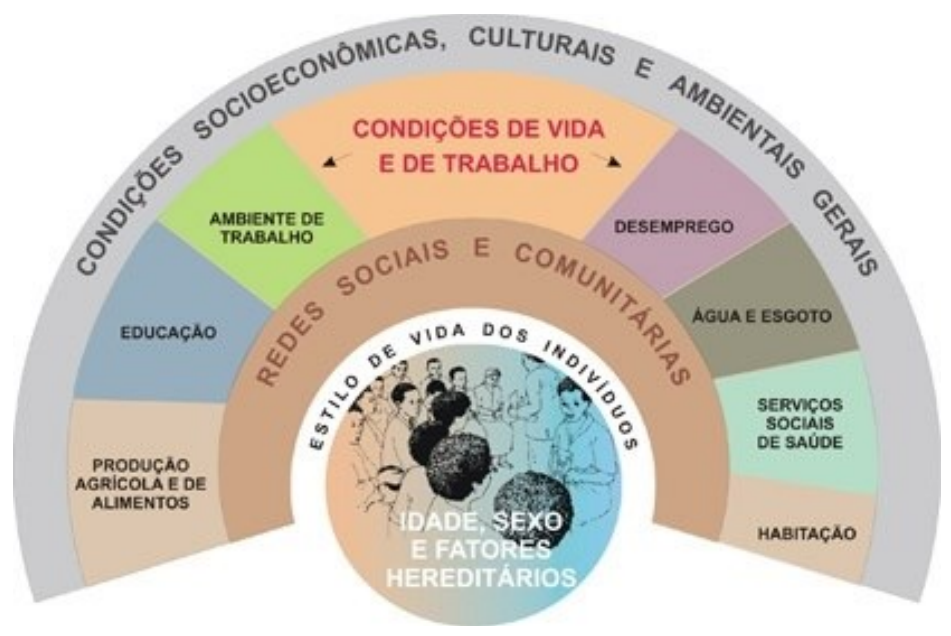

Fonte: Dahlgren e Whitehead (1991, p. 11)

Esse modelo apresenta as inter-relações entre indivíduo e sociedade. Na base, encontram-se os fatores individuais ou microdeterminantes caracterizados pelos aspectos herdados, responsabilidade no grupo familiar de inserção e possibilidades de novos vínculos. As redes sociocomunitárias, no modelo, são laços de coesão, relações solidárias e de confiança em que os indivíduos se inserem. Na condição de vida e trabalho, os indivíduos acessam bens e serviços públicos, trabalham, residem e se deslocam da casa para o trabalho ou escola e vice-versa.

Dependendo do ambiente de trabalho, das condições de moradia e de acesso à educação, saneamento e água, os indivíduos podem adoecer mais pelas condições precárias que lhes são impostas ou acessíveis. Por fim, têm-se as condições socioeconômicas, culturais e ambientais gerais ou macrodeterminantes ${ }^{6}$, cuja responsabilidade está a cargo dos órgãos de estado e governo no estabelecimento de políticas de trabalho, educação, econômica e promoção da saúde, afetando todas as camadas anteriores (LAURELL, 1983; BUSS, 2007). Boa parte desses determinantes possui expressão territorial complexa e foram endereçados por autores do Serviço Social.

As múltiplas expressões da questão social, caracterizadas pelas situações de vulnerabilidade social, pelo desemprego estrutural, pela violação dos direitos, pela falta de saneamento básico, pela violência urbana e a familiar, entre outras, vivenciadas pela população brasileira, evidenciam o quanto a problematização e a compreensão das configurações atuais fazem parte dos objetivos do processo de trabalho profissional. Assim, captar a dinâmica da realidade social significa reconhecer os movimentos de resistência e superação por parte da classe trabalhadora das adversidades impostas pelos ideários neoliberais. (MACIEL; FERNANDES, 2011, p.162)

Como afirma Barcellos (2002), se a doença é uma manifestação do indivíduo, a situação de saúde pode ser entendida como manifestação do lugar. Ainda segundo o autor, as condições particulares de produção de um agravo ou doença estão intrinsecamente relacionadas à acumulação de situações históricas, ambientais e sociais dos lugares onde ocorrem. É possível a caracterização de um território como vulnerabilizado quando se estudam os DSS de sua população. Com efeito, tal vulnerabilidade de populações 
se concretiza a partir da articulação de alguns desses determinantes sociais expressos num arranjo que associa fatores estruturais, como as desigualdades sociais geradas pelas contradições inerentes ao modo de produção e distribuição de renda, e aspectos do cotidiano da vida nesses territórios, como hábitos culturais e costumes sanitários.

Portanto, as TSS - do seu processo de construção ao de aplicação - devem apontar para um sentido de transformação do território e seus grupos sociais, nos diferentes níveis do local ao global, sem, necessariamente, estabelecer primazia entre escalas espaciais. Diferente das tecnologias convencionais por natureza vinculadas a protagonismos de ordem financeiro-econômica -, as TSS devem produzir processos formativos, de pesquisa e de intervenção em políticas públicas, formulados por via de elementos e situações da realidade vivida, emersos das necessidades dos atores locais.

Para atender a essas condições, devem refletir a população definida em sua relação com o lugar, organizações de base comunitária e movimentos sociais perceptíveis implicados com mudanças das condições materiais de vida singulares àquele território, uma vez que os territórios ${ }^{7} \operatorname{com}$ alta vulnerabilidade socioambiental inseridos nos grandes centros urbanos apresentam intrincados desafios no combate às iniquidades $^{8}$. Entre eles, o estigma alimentado por uma cultura fundada na apatia política, na descrença na coisa pública e na dissolução de perspectivas de transformação real do território por parte dos moradores agrava o cotidiano já contaminado por um violento controle social exercido sobre a maioria dos seus moradores. Há constante violação de direitos civis e políticos por aparelhos de coerção públicos e privados; pouco acesso a direitos sociais (educação, saúde/ambiente, habitação, etc.); alto desemprego e precarização acentuada do trabalho; baixa escolaridade e acesso restrito à saúde pública; condições ambientais deterioradas; população empobrecida, desprovida também de capital social e cultural; políticas públicas assistencialistas e paternalistas; cultura de massa incentivando ação individualista e fragmentada; criminalização do território (MEDEIROS, 2008; LIMA; BUENO, 2010).

O olhar que "condena" este território favelizado está presente no seu interior e é, principalmente, exercido de fora para dentro, seja pela produção midiática e simbólica sobre Manguinhos, seja pelo preconceito contra quem lá reside, trabalha ou transita. Dados do censo domiciliar e empresarial de Manguinhos (RIO DE JANEIRO, 2010), de pesquisas conduzidas por Cavallieri e Lopes (2008) e Cavallieri e Vial (2012), apontam para uma população de aproximadamente 40 mil pessoas residindo no território ampliado de Manguinhos. O perímetro registra o quinto pior Índice de Desenvolvimento Humano (IDH) do município do Rio de Janeiro, com apenas 2,7\% da população chegando à universidade. Enquanto a expectativa de vida no lugar é de 57,4 anos, no Méier, bairro circunvizinho, essa média chega aos 72 anos (HASENBALG, 2004).

Ressalta-se a dificuldade de circulação limitada por barreiras visíveis e invisíveis, impedindo o ir e vir não só de moradores como de serviços públicos essenciais, sendo uma característica marcante desse território, cujo interior e circunvizinhanças exigem novos modos relacionais com os entes governamentais responsáveis pela elaboração de políticas públicas, desafiando a capacidade de inovar e conceber tecnologias que sejam adequadas ao atendimento das demandas da população, para transformação da sua qualidade de vida.

Nem as características gerais dos territórios marginalizados e nem as especificidades de Manguinhos podem ser abordadas por soluções emergenciais ou pontuais; demandam enfrentamento das iniquidades estabelecidas de modo estruturante e transversal. A necessidade de criar soluções em resposta a problemas vinculados à pobreza e à exclusão social fez surgir uma geração de capacidades em cujas propostas estivessem contempladas inovações sociotécnicas, com dinâmicas e processos de (re)significação de tecnologias efetivas em mudanças em múltiplas dimensões da vida social. Enfrentar as iniquidades com uma abordagem intersetorial já se apresenta como um caminho para melhoria da qualidade de vida e saúde. O conceito de Tecnologias Sociais se insere nesse panorama. 


\section{A experiência de TSS da Fiocruz}

A Fundação Oswaldo Cruz conta com unidades técnico-científicas e escritórios nas diferentes regiões do Brasil $^{9}$, o que faz com que se depare com uma diversidade de problemas, caso a caso. No entanto, todas estão circundadas por territórios que, embora não sejam sempre favelizados, apresentam intenso processo de transformação, dado, sobretudo, pela mudança na quantidade de ocupantes e nos usos no território ${ }^{10}$. A filiação histórica da Fiocruz ao ideário da determinação social da saúde a leva a reconhecer como fatores estruturais - essenciais à melhoria das condições de saúde e qualidade de vida da população -, a constituição e "o manejo de políticas públicas que articule os atores sociais em torno de um projeto de desenvolvimento sustentável e includente" (FIOCRUZ, 2010).

No Brasil, o Ministério da Saúde (MS) orienta práticas em ciência, tecnologia e inovação em saúde através de sua Secretaria de Ciência, Tecnologia e Insumos Estratégicos (SCTIE), encarregada da implementação das políticas de assistência farmacêutica, de avaliação e incorporação de tecnologias no Sistema Único de Saúde e de incentivo ao desenvolvimento científico e tecnológico em saúde. Essa secretaria é responsável pelo incentivo ao desenvolvimento de pesquisas em saúde no país, de modo a direcionar os investimentos realizados pelo Governo Federal às necessidades da saúde pública (BRASIL, 2013). A orientação abarca tanto as pesquisas no desenvolvimento de produtos e processos como protocolos, procedimentos e pareceres, além de rotinas, fluxos e recomendações para tomadas de decisão na gestão (BRASIL, 2008).

Dada a combinação de arranjo hierárquico, de um lado, e orientações e atribuições, de outro, muitos são os compromissos diretamente alinhados à questão dos DSS assumidos pela Fiocruz, não somente como órgão de pesquisa do Ministério da Saúde, mas como expoente da Epidemiologia Crítica e dos movimentos de saúde pública e saúde coletiva que levaram à transformação do sistema de saúde e assistência no Brasil.

\section{Metodologia}

A proposta de construção de dimensões estruturantes de TSS se fundamentou na análise das contribuições das equipes participantes de dois editais de fomento da Fiocruz. Em 2009 (2009/2010/2011) e 2011 (2011/2012/2013), a Fiocruz, por meio de sua Coordenadoria de Cooperação Social, promoveu dois editais de apoio ao desenvolvimento de TSS pelas suas unidades técnico-científicas e administrativas, com o objetivo de fomentar resultados, impactos e mudanças qualitativas na saúde e nas condições de vida das populações em territórios vulnerabilizados.

A proposta de construção e apropriação de conhecimento a partir do desenvolvimento de TSS se voltou prioritariamente para a emancipação dos atores envolvidos, sendo concebida por meio do conhecimento popular intercambiado com o saber técnico-científico. Forneceu como legado ferramentas metodológicas e, especialmente, o capital crítico necessário ao delineamento de horizontes de transformação social.

Foram apoiados quarenta e seis projetos, sendo dezesseis no primeiro e vinte no segundo. Os projetos versaram em três eixos temáticos: (1) Educação, Comunicação e Cultura; (2) Trabalho, Renda e Solidariedade; (3) Território, Saúde e Ambiente. Em ambos momentos as iniciativas visaram resultados, impactos e mudanças qualitativas na saúde e nas condições de vida das populações em territórios vulnerabilizados, partindo do pressuposto de adaptabilidade, em escalas e contextos variados, desse aprendizado, pois: 
Na prática, o que se verifica é que muitas experiências de TS necessitam de uma sistematização para que possam ser reaplicadas em outras comunidades e, com isso, contribuam com o incremento de alternativas para a superação das condições adversas em que se encontra parcela significativa da população brasileira (MACIEL; FERNANDES, 2011, p. 163).

A experiência do segundo momento estimulou a articulação das equipes de projeto em redes intra e interinstitucional - preferencialmente com organizações do movimento social - por compreender-se que os projetos construídos em parcerias, desde a sua elaboração com a sociedade civil organizada, tendem a gerar resultados mais significativos no desenvolvimento das ações.

Foi proposto o desafio da construção de TSS na convergência de atuação do Ministério da Saúde, do Ministério da Ciência, Tecnologia e Inovação - MCTI que envolve "Ciência, Tecnologia e Inovação para o Desenvolvimento Social". As vinte iniciativas da segunda edição envolveram, em média, doze participantes em cada uma das equipes de projeto.

As experiências e reflexões do primeiro momento propiciaram ao segundo, em 2011, uma revisão nos processos desde a concepção ao monitoramento junto às equipes envolvidas. Pactuou-se junto às equipes um acompanhamento participativo das ações em desenvolvimento. A partir de uma metodologia, em que a cada encontro eram discutidos e propostos os posteriores, construiu-se uma agenda com seminários reflexivos, oficinas temáticas e encontros de acompanhamento.

Durante os encontros, foram debatidas questões relativas ao universo de execução dos projetos, como também propostas teórico-metodológicas onde se apontaram as necessidades de conceitos sobre as práticas em desenvolvimento. A meta era encontrar respostas para perguntas como: o que são tecnologias sociais em saúde? Qual o objeto tecnológico de cada uma delas? Qual a melhor metodologia para desenvolvê-las? A partir desses e de outros questionamentos comuns aos participantes das equipes do segundo edital, acordou-se um modelo de acompanhamento formativo, no qual as equipes pudessem expor suas dificuldades, discutir a cada encontro e compartilhar limites, possibilidades e desafios comuns.

\section{Caráter participativo e formativo do acompanhamento}

A construção de conhecimentos e execução dos projetos foram subsidiadas por dois seminários reflexivos sobre TS, com a presença de pesquisadores e convidados de universidades, movimentos sociais, organizações não-governamentais e representante da FINEP. Elaboraram-se duas oficinas temáticas e quatro encontros de acompanhamento bimensais com a participação das vinte equipes, num total entre cinquenta e oitenta pessoas, em média, para cada um dos três momentos (seminários, oficinas e encontros de acompanhamento), no período compreendido de novembro de 2011 a setembro de 2012.

Os dois seminários e as oficinas temáticas foram compostos por equipes ampliadas dos projetos aprovados (agentes locais, lideranças comunitárias, pesquisadores e bolsistas dos projetos), por estudantes de pós-graduação, gestores e demais pesquisadores e profissionais interessados na temática. Apenas os encontros de acompanhamentos bimensais foram restritos às equipes ampliadas dos projetos.

O primeiro seminário, em março de 2012, versou sobre conceitos, práticas e monitoramento aplicados à TS. No segundo, em setembro do mesmo ano, foram elencadas e debatidas experiências de TS em construção, com a participação de pesquisadores da Fiocruz, contribuição dos movimentos sociais para o debate e implementação de projetos dessas tecnologias em territórios com risco social, além da apresentação de abordagens de acesso à cultura sociotécnica e à produção compartilhada de conhecimento, a partir de experiências de ensino, pesquisa e extensão universitária. 
As oficinas temáticas realizadas na mesma ocasião dos seminários, em março e setembro de 2012, objetivaram a troca de saberes dos participantes envolvidos. A primeira delas versou sobre a necessidade e a importância de conceitos relativos às TS e TSS e se estes refletiam ou não as iniciativas em andamento na Fiocruz. Contribuiu, portanto, para a concepção de temáticas que fornecessem subsídios para a compreensão sobre as práticas dos projetos

A segunda objetivou definir dimensões estruturantes das TSS, a partir de três condicionantes importantes na discussão e elaboração de suas dimensões constitutivas: abordagens conceituais, elementos constitutivos e suas relações com diferentes disciplinas do conhecimento e políticas de desenvolvimento das ações As discussões tomaram lugar a partir de grupos de trabalho (GT), sendo um discutindo a temática participação social e territorialidade (GTPST), e o outro enfocando construção do conhecimento e transformação social (GTCCTS), ambos referidos aos três eixos acima e visando à elaboração das dimensões estruturantes de TSS.

\section{Dinâmica dos GTPST e GTCCTS}

A dinâmica metodológica do GTPST e GTCCTS transcorreu conforme questões norteadoras para o debate, de modo a possibilitar a discussão dos condicionantes apontados como importantes na elaboração das dimensões. O GTPST contou com vinte oito participantes e o GTCCTS com trinta e cinco, sendo o primeiro dividido em dois grupos e o segundo em três. Cada um dos subgrupos desdobrados dos dois GTs contou com a participação de dois relatores e um mediador. Abaixo elencam-se as questões que nortearam o debate:

- Como identificar o potencial transformador da realidade de uma TSS?

- Em que medida o conhecimento produzido por todos os envolvidos é apropriado pelos atores interessados na transformação social?

- Qual a importância da articulação dos atores ligados a TSS com políticas públicas?

- Como considerar/inserir a transformação social no monitoramento e avaliação da TSS?

- Qual a relação que se estabelece entre pesquisador e comunidade?

- Como são trocadas informações sobre as necessidades do território?

- Será que a forma como pensamos as necessidades de uma população são convergentes com as esperadas por elas?

- Em que contexto se produz uma tecnologia social? A quem ela vai servir? Para que vai servir?

\section{Discussões e resultados: elementos estruturantes de TSS}

Elementos da análise qualitativa de conteúdo, propostos por Becker (1994), Minayo (2004) e Bardin (2009), orientaram a seleção das contribuições produzidas pelos GTs. Os conteúdos-elementos foram consolidados a partir de ideias-chave recorrentes, associando-as a possíveis dimensões de TSS referidas aos territórios vulneráveis socialmente. Procurou-se seguir a análise do processo de produção de conhecimento, segundo Thomas e Fressoli (OLIVEIRA et al, 2011).

A partir da dinâmica de construção e sistematização do conhecimento produzido pelos participantes dos GTs foi possível identificar quatro ideias essenciais, que emergiram dos relatórios das oficinas, relacionáveis como dimensões constitutivas de TSS em territórios vulneráveis. Além de a própria 
dinâmica ser percebida como Dimensão Participativa e Formativa, foram entendidas como dimensões contribuintes à compreensão da complexidade dos territórios:

Dimensão da Pesquisa-Ação: Essa dimensão abarca o caráter da pesquisa visando ao desenvolvimento de projetos ou políticas. Na pesquisa-ação, fortalece-se e encurta-se a relação entre teoria e prática; favorecem-se alianças e comunicações entre pesquisadores e atores; persegue-se um duplo objetivo de conhecimentos a desenvolver (pesquisa) e de situações a modificar (ação); produz-se um novo saber na e para ação e contribui-se no processo de tomada de decisão para resolução de problemas (DIONNE, 2007).

Dimensão Pedagógica: Diz respeito à educação coletiva e remete ao campo da formação, sendo um instrumento capaz de tornar possível o conhecer e vislumbrar outros horizontes, viabilizando ações que apenas seriam exequíveis pela colaboração conjunta de um grupo. Possibilita a emancipação de atores sociais pela construção de saberes, que se evidenciam na ação de fazer e refazer. Também enfoca o campo metodológico claro de intervenção, envolvendo o compromisso de todas as partes interessadas, colaborando e potencializando a troca de saberes e favorecendo o aprendizado recíproco. Orientou-se pela mudança de visão do pesquisador de que "favela é lugar apenas de carência. É lugar de produção de ciência e conhecimento".

Dimensão Comunicativa: Na dimensão comunicativa, apontada no âmbito da relação pesquisador/comunidade, é preciso que a troca entre eles se faça desde a concepção de um projeto ao seu desenvolvimento e compartilhamento dos resultados. A apropriação se dá no âmbito do "como", pois o objetivo difere de uma iniciativa para outra, além do resultado desejado, mas o modo de fazer pode assemelhar-se. A clareza do problema a ser enfrentado e dos papeis de cada ator envolvido no processo é de fundamental importância para a contribuição dessa dimensão. A metodologia, construída coletivamente, deve estar descrita de modo claro e possibilitar sua aplicação por todos que participam da ação.

Dimensão de Política Pública: Tendo em vista que as demandas das comunidades são bem maiores que o aporte de recursos oferecidos pelo poder público, defendeu-se o reforço de iniciativas já existentes com alianças entre diferentes secretarias das esferas municipais, estaduais e federais para consecução dos objetivos de uma dada tecnologia. Os projetos assumidos devem configurar compromisso institucional, garantindo a continuidade das ações após entrada nas comunidades, validando e monitorando sua aplicação com vistas ao desdobramento em políticas públicas. TSS requerem projetos de curto, médio e longo prazo, dependendo das características e necessidades dos territórios e seus mecanismos de construção coletiva.

\section{Resultados e perspectivas}

Os subgrupos de trabalho apontaram, acerca de como a transformação social se relaciona com a configuração de elementos estruturantes formuladores de TSS, que:

- Necessita-se refletir qual modelo acadêmico se deseja, qual o papel da instituição de pesquisa e qual tecnologia é necessária. São necessários novos parâmetros, novos indicadores.

- A transformação social é mais que mudança de qualidade de vida. Significa ultrapassar preconceitos e criar melhores condições de sociabilidade; 
- A transformação deve ser algo que todos desejem, pois deriva de articulação intersetorial e de participação popular. Os sujeitos envolvidos devem ter consciência de que tipo de mudança almejam implementar;

- As mudanças culturais de uma instituição, por exemplo, dependem de que todas as pessoas que interagem com esta cultura apontem problemas e a necessidade de transformação;

- O potencial transformador está no planejamento em conjunto com os movimentos sociais desde a identificação das demandas, reuniões com os sujeitos interessados e pactuação de objetivos e resultados;

- A comunidade tem a experiência local. Deve ter espaço nos debates promovidos pelas instituições de pesquisa para manifestarem pensamento e opinião;

- Pensar políticas de ciência, tecnologia e sociedade passa pelo desenho que envolve a relação de confiança das comunidades, os tempos requeridos e reformas curriculares que contemplem os entendimentos disciplinares.

Ambas as edições de fomento possibilitaram resultados bastante expressivos como a concepção participativa de cursos técnicos e especializações na modalidade jovem e adulta; a implementação de melhorias no abastecimento de água; a organização de serviços de diagnóstico em área rural endêmica; a criação de conselhos de saúde local e modelos de comunicação participativos sobre condições nocivas à saúde socioambiental, denunciadores de condições de degradação local. Tais resultados possibilitaram o desenvolvimento de processos formativos e de produtos concebidos e apropriados pelos atores envolvidos, relativos às questões sociais do território. Isso foi possível pelo fato de a formulação e implementação se caracterizarem pela participação social/popular, mediante práticas metodológicas aplicadas na modelagem de tecnologias e ações territorializadas dos atores.

Entre 2013 e 2014, a Fiocruz apresentou 27 Indicadores de Cooperação Social para avaliação de projetos aprovados nos novos editais da entidade, conjugando a experiência anterior da instituição, aqui descrita, e a metodologia do Instituto de Tecnologia Social (ITS) para o Sistema de Acompanhamento de Tecnologias Sociais para Universidades (SATECS/UNI) (FIOCRUZ, 2014). Estes foram organizados segundo quatro dimensões que guardam muita correspondência com aquelas aqui definidas, mas não são idênticas, uma vez que - de maneira diversa da metodologia anterior - foram desenvolvidas por meio de um único Grupo de Trabalho, formado exclusivamente por profissionais designados por unidades da Fundação, em debate com algumas personalidades e pesquisadores afeitos à temática.

Tabela 1 - Nomenclaturas de 2009 a 2014 em uso na Fiocruz

\begin{tabular}{|c|c|}
\hline $\begin{array}{c}\text { Nomenclatura 2009-2012: } \\
\text { Dimensões de tecnologias sociais a serem } \\
\text { reconhecidas nos projetos }\end{array}$ & $\begin{array}{c}\text { Nomenclatura 2013-2014 } \\
\text { Dimensões cooperativas a serem reconhecidas } \\
\text { nos projetos }\end{array}$ \\
\hline Dimensão Participativa e Formativa & Gestão participativa e cidadania \\
\hline Dimensão da Pesquisa-Ação & Conhecimento, território e saúde \\
\hline Dimensão de Política Pública & Relevância social \\
\hline Dimensão Comunicativa: & Processo formativo dialógico \\
\hline Dimensão Pedagógica & \\
\hline
\end{tabular}

Fonte: Sistematização realizada pelas autoras. 
A diferença de nomenclaturas aparece na Tabela 1, em que é sugerida uma certa correspondência - embora não seja a única possível, isto é, não cristaliza as semelhanças e diferenças entre elas. Por exemplo: embora o ITS não se especialize em saúde nem em territórios vulneráveis, é uma instituição de referência em tecnologias sociais; paradoxalmente, segundo o documento "Indicadores em Cooperação Social 2014", não teria sido consenso entre seus 14 representantes, o conceito de tecnologias sociais construído anteriormente em um contexto de interação direta com os segmentos das comunidades implicadas. Deste modo, tornou-se inescapável sublinhar, no mesmo documento, que estas novas dimensões e seus indicadores ainda carecem de mecanismos consolidados de validação.

\section{Considerações finais}

Pela sua natureza mobilizadora e integradora, estes editais - que continuam sendo publicados ensejaram a emergência de uma metodologia e de uma "cartografia" do conceito de tecnologias sociais em saúde muito úteis para o trabalho de equipes multidisciplinares, em ações/estratégias multiinstitucionais e multissetoriais - arranjo no qual é crescente a inserção de profissionais e pesquisadores oriundos das áreas de Ciências Sociais e Serviço Social.

Os achados apresentados neste artigo não esgotam as possibilidades de leitura e de compreensão dos processos saúde-doença em territórios vulneráveis; pelo contrário, encorajam a descoberta de mecanismos que permitam interação entre organizações e evitem a proposição de soluções que repitam fórmulas gerais, maiormente prescritivas. Nesse sentido, a metodologia participativa aqui descrita é particularmente indicada para o desenvolvimento de ações conjugadas a políticas públicas, pois oferece instrumentos de validação que podem ser incorporados pelos públicos-alvo de tais ações. Ao conjugar abrangência e especificidade, indica, também, potencial de aplicabilidade a outros territórios e propósitos.

\section{Referências}

BARCELLOS, Christovam de Castro et al. Organização espacial, saúde e qualidade de vida: análise espacial e uso de indicadores na avaliação de situações de saúde. Inf. Epidemiol. Sus, Brasília, v. 11, n. 3, set. 2002. Disponível em: http://scielo.iec.pa.gov.br/scielo.php?script=sci arttext\&pid=S0104-16732002000300003\&lng=pt\&nrm=iso. Acesso em: 15 ago. 2015.

BARDIN, Laurence. Análise de Conteúdo. Lisboa: Edições 70, 2009.

BAUMGARTEN, Maíra. Conhecimento, planificação e sustentabilidade. São Paulo Perspec., São Paulo, v. 16, n. 3, p. 31-41, julho 2002 Disponível em: http://www.scielo.br/scielo.php?script=sci arttext\&pid=S0102-88392002000300005\&lng=en\&nrm=iso. Acesso em: 15 ago. 2015.

BAZZO, Walter Antonio. Ciência, tecnologia e sociedade e o contexto da educação tecnológica. Florianópolis: Ed. UFSC, 1998. BECKER, Howard Saul. Métodos de pesquisa em ciências sociais. São Paulo: HUCITEC, 1994.

BODSTEIN, Regina; ZANCAN, Lenira. Avaliação das ações de promoção da saúde em contextos de pobreza e vulnerabilidade social, pp. 39-59. In: Zancan, L; Bodstein, R; Marcondes, W.B. (Orgs.). Promoção da saúde como caminho para o desenvolvimento local. Rio de Janeiro: Abrasco, 2002.

BRASIL. Ministério da Saúde. Secretaria de Ciência Tecnologia e Insumos Estratégicos. Departamento de Ciência e Tecnologia. Política Nacional de Ciência, Tecnologia e Inovação em Saúde/Ministério da Saúde. 2. Ed. Brasília: Ministério da Saúde, 2008.

BRASIL. Fundação Oswaldo Cruz. Fiocruz como instituição pública estratégica de Estado para a saúde. CONGRESSO INTERNO DA FIOCRUZ. VI. 18-22 out. 2010. Relatório Final. Disponível em: http://www.fiocruz.br/media/relatorio final ultima versao.pdf. Acesso em: 15 ago. 2015.

BRASIL. Ministério da Saúde. Secretaria de Ciência, Tecnologia e Insumos Estratégicos (SCTIE). Apresentação. Disponível em: http://portal.saude.gov.br/portal/saude/Gestor/visualizar texto.cfm?idtxt=3042. Acesso em: 15 ago. 2015.

BREILH, Jaime. Epidemiologia crítica: ciência emancipadora e interculturalidade. Rio de Janeiro: Fiocruz, 2006.

. Precisamos ter um novo viver, com taxas de crescimento menos agressivas, mas com mais qualidade. Revista POLI: saúde,

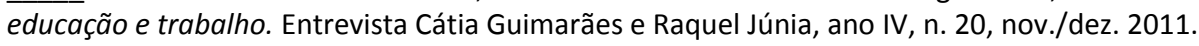


BUSS, Paulo Marchiori; PELLEGRINI FILHO, Alberto. A saúde e seus determinantes sociais. PHYSIS: Rev. Saúde Coletiva, Rio de Janeiro, ano 17, n.1, p.77-93, 2007.

CAVALLIERI, Fernando et al. Índice de Desenvolvimento Social - comparando as realidades microurbanas da cidade do Rio de Janeiro. Coleção Estudos Cariocas, ed. n. 8, texto n. 20080401, abril, 2008. Diretoria de Informações Geográficas. Instituto Municipal de Urbanismo Pereira Passos (IPP). Prefeitura da Cidade do Rio de Janeiro. Disponível em: http://portalgeo.rio.rj.gov.br/estudoscariocas/download/2394 IndicedeDesenvolvimentoSocial IDS.pdf. Acesso em: 15 ago. 2015.

; VIAL, Adriana. Favelas na cidade do Rio de Janeiro: o quadro populacional com base no Censo 2010. Coleção Estudos Cariocas, ed. n. 12, texto n. 20120501, maio 2012. Secretaria Extraordinária de Desenvolvimento. Instituto Municipal de Urbanismo Pereira Passos (IPP). Prefeitura da Cidade do Rio de Janeiro. Disponível em: http://portalgeo.rio.rj.gov.br/estudoscariocas/download/3190 FavelasnacidadedoRiodeJaneiro Censo 2010.PDF. Acesso em: 15 ago. 2015.

COMISSÃO Nacional sobre Determinantes Sociais da Saúde. As causas sociais das iniquidades em Saúde no Brasil. Relatório Final da Comissão Nacional sobre Determinantes Sociais da Saúde, abril 2008. Disponível em: http://bvsms.saude.gov.br/bvs/publicacoes/causas sociais iniquidades.pdf. Acesso em: 15 ago. 2015.

DAGNINO, Renato; BRANDÃO, Flávio Cruvinel; NOVAES, Henrique. Sobre marco analítico conceitual da tecnologia social. In: LASSANCE JR., A. et al. Tecnologia Social - uma estratégia para o desenvolvimento. Rio de Janeiro: Fundação Banco do Brasil, 2004. DAHLGREN, G; WHITEHEAD, M. Policies and strategies to promote social equity in health. Stockholm: Institute for Future Studies, 1991.

DIONNE, Hughes. A pesquisa-ação para o desenvolvimento local. Brasília: Líber Livro, 2007.

FIOCRUZ. Indicadores de Cooperação Social. Coordenadoria de Cooperação Social, 2014. Disponível em: https://portal.fiocruz.br/sites/portal.fiocruz.br/files/documentos/indicadores em cooperacao social2014.pdf. Acesso em: 15 ago. 2015.

HAESBAERT, Rogério. 0 mito da desterritorialização: do "fim dos territórios" à multiterritorialidade. Rio de Janeiro: Bertrand Brasil, 2004.

HASENBALG, Carlos. Educação. In: CARDOSO, Adalberto (Coord.). Desenvolvimento humano e condições de vida na cidade do Rio de Janeiro. Coleção Estudos Cariocas, n. 4, texto n. 20040101, jan. 2004, p 130-175. Secretaria Municipal de Urbanismo. Convênio IUPERJ/IPEA/IPP/Prefeitura da Cidade do Rio de Janeiro. Disponível em: http://www.armazemdedados.rio.rj.gov.br e http://portalgeo.rio.ri.gov.br/estudoscariocas/download/2352 RelatoriodeDesenvolvimento Humano.pdf. Acesso em: 15 ago. 2015.

LAURELL, A.C. A saúde-doença como processo social. In: NUNES, E.D. Medicina social: aspectos históricos e teóricos. Global, 1983. LEONTIEV, Alexis Nikolaevich. O desenvolvimento do psiquismo humano. São Paulo: Moraes, 1972.

LIMA Carla; BUENO, Leonardo Brasil. Território, participação popular e saúde: Manguinhos em debate. 1.ed. Rio de Janeiro: Ediouro/ENSP/Fiocruz, 2010.

MACIEL, Ana Lúcia Suárez; FERNANDES, Rosa Maria Castilhos. Tecnologias sociais: interface com as políticas públicas e o Serviço Social. Serv. Soc. Soc., São Paulo, n. 105, p. 146-165, mar. 2011. Disponível em: http://www.scielo.br/scielo.php?script=sci arttext\&pid=S0101-66282011000100009\&lng=en\&nrm=iso. Acesso em: 15 ago. 2015. MARTINELLI, Maria Lúcia. Serviço social na área de saúde: uma relação histórica. Revista Intervenção Social, Lisboa, n. 28, p. 0918, 2014.

MEDEIROS, Cristina Maria Barros de. A construção coletiva dos direitos da cidadania e justiça. In: Seminário Internacional Direitos Humanos, Violência e Pobreza. II. Anais... Rio de Janeiro: Rede Sirius/UERJ, 2008, v.1.

. Diálogos com a superação: sobre formação, qualificação profissional e reconstrução de histórias de vida de deficientes visuais. 2010. 235 p. Tese (Doutorado) - Programa de Pós-Graduação em Engenharia de Produção, Universidade Federal do Rio de Janeiro, Rio de Janeiro: UFRJ/COPPE, 2010.

MINAYO, Cecília Souza. O desafio do conhecimento: pesquisa qualitativa em saúde. 8. ed. São Paulo: Hucitec, 2004.

MOTTER, D. G.; ALVES, J. M. de. Construção do princípio de integralidade: percepções e ações desencadeadas pela equipe de saúde da família quanto às demandas sociais apresentadas no município de Londrina - PR. Serviço Social em Revista, v. 8, n. 2, Londrina, jan./jun. 2006.

NOVAES, Henrique; DIAS, Rafael de Brito. Construção do marco analítico-conceitual da tecnologia social. In: DAGNINO, Renato (Org.). Tecnologia social: uma ferramenta para construir outra sociedade. 2.ed. Campinas, SP: Komedi, 2010.

OLIVEIRA, S. C., COSTA, E. H. S., DAGNINO, Renato, FARIA, L. I. L. A tecnologia social sob análise: uma avaliação de possíveis indicadores. In: HOFFMANN, W. A. M. Ciência, tecnologia e sociedade. São Carlos: Ed UFCar, 2011.

ORGANIZAÇÃO PAN-AMERICANA DA SAÚDE. Eliminação de Doenças Negligenciadas e Outras Infecções Relacionadas à Pobreza. 49 Conselho Diretor. Resolução 19 - CD 49.R19. Organização Mundial da Saúde. Washington, D.C., EUA, 28 set. $/ 2$ out. 2009. 
PASTOR, Marcia. A democratização da gestão da política de assistência social: fragmentos de um estudo. Katálysis, Florianópolis, v. 10. n. 2, jul./dez. 2007.

RIO DE JANEIRO. Escritório de Gerenciamento de Projetos do Governo do Rio (EGP-RIO). Complexo de Manguinhos. Censo Domiciliar. Relatório Técnico, mar. 2010. Secretaria de Estado da Casa Civil do Rio de Janeiro. Disponível em: http://arquivos.proderi.ri.gov.br/egprio imagens/Uploads/MD.pdf. Acesso em: 15 ago. 2015.

SIMIONATTO, Ivete; COSTA, Carolina Rodrigues. Estado e políticas sociais: a hegemonia burguesa e as formas contemporâneas de dominação. Katálysis, Florianópolis, v. 17, n. 1, p. 68-76, jun. 2014. Disponível em: http://www.scielo.br/scielo.php?script=sci arttext\&pid=S1414-49802014000100007\&lng=en\&nrm=iso. Acesso em: 16 ago. 2015. THOMAS, Hernán. Tecnologías sociales y ciudadanía socio-técnica. Notas para la construcción de la matriz material de un futuro viable. Revista Ciência e Tecnologia Social CTS, n. 1. 2011. Disponível em: http://seer.bce.unb.br/index.php/cts/index>UnB, 2011. Acesso em: 15 ago. 2015.

WHITEHEAD, Margaret. The concepts and principles of equity and health. Program on Health Policies and Planning of the WHO Regional Office for Europe. Copenhagen: WHO, 2000. Disponível em: http://salud.ciee.flacso.org.ar/flacso/optativas/equity and health.pdf. Acesso em: 15 ago. 2015.

${ }^{1}$ Além da presença da Fiocruz, a região conta com o Terminal de Cargas da Empresa Brasileira de Correios e Telégrafos (ECT), a Refinaria de Manguinhos de Petróleo, entre outras empresas públicas. Várias empresas privadas evadiram-se do território, como a General Electric, Embratel, Conab, Souza Cruz entre outras.

2 Citamos as contribuições de Oswald Spengler (1880-1936), José Ortega y Gasset (1883-1955), Ludwig Wittgenstein (18891951), Martin Heidegger (1889-1976), Walter Benjamin (1892-1940), Lewis Mumford (1895-1990), Max Horkheimer (18951973), Herbert Marcuse (1898-1979), Theodor Adorno (1903-1969), Arnold Gehlen (1904-1976), Mário Ferreira dos Santos (1907-1968), André Leroi-Gourhan (1911-1986), E.F. Schumacher (1911-1977), Jacques Ellul (1912-1994), Mario Bunge (1919), Vilém Flusser (1920-1991), Gilbert Simondon (1924-1989), Jean-François Lyotard (1924-1998), Ivan Illich (1926-2002), Jean Baudrillard (1929-2007), Jürgen Habermas (1929-) Jacques Derrida (1930-2004), Andrew Feenberg (1943-), James R. Beniger (1947-2010), Bernard Stiegler (1952- ), dentre outros.

${ }^{3}$ Ver, a este respeito, o percurso histórico exaustivamente reconstruído com objetividade por Martinelli (2003)

${ }^{4}$ Não foi citada a página, pois apenas a versão digital foi encontrada. Com as ferramentas de busca por palavra, é fácil localizar a citação integralmente.

${ }^{5}$ Os diversos estudos sobre os DSS e as iniquidades em saúde permitiram a construção de modelos que procuram esquematizar a trama de relações entre os vários níveis de determinantes sociais e a situação de saúde. Entre estes modelos, a Comissão Nacional sobre Determinantes Sociais da Saúde (CNDSS) resolveu adotar o de Dahlgren e Whitehead (1991), que serve de base para orientar a organização de suas atividades e os conteúdos do presente relatório. Apesar da existência de outros modelos mais complexos, que buscam explicar com maiores detalhes as relações e mediações entre os diversos níveis de DSS e a gênese das iniquidades, a escolha do modelo de Dahlgren e Whitehead se justifica por sua simplicidade, sua fácil compreensão para vários tipos de público e pela clara visualização gráfica dos diversos DSS (CNDSS, 2008).

${ }^{6}$ Simionatto e Costa (2014) fazem uma consideração afiada a respeito da situação contemporânea da saúde pública e de um discurso recorrente que promove a privatização: afirmam que não se deve somente "a problemas de gestão da coisa pública", mas, sobretudo, a "medidas neoliberais, que desde os anos 1990 colocaram em cheque as políticas sociais universalistas, incompatíveis com a política macroeconômica e as restrições do Estado na área social".

7 Entendido conforme Haesbaert (2004), que propõe a amplitude do tema perpassando várias áreas do conhecimento: a Geografia com a ênfase na materialidade do território em suas múltiplas dimensões; a Ciência Política na construção a partir das relações de poder; a Economia que destaca a base de produção; a Antropologia no realce à dimensão simbólica do território; a Sociologia que focaliza a sua intervenção nas relações sociais; e a Psicologia que incorpora o território no debate sobre a construção da subjetividade. $O$ autor admite a presença de uma polissemia conceitual em relação ao conceito de "território" e apresenta uma síntese das várias noções, agrupando-as em três vertentes básicas.

${ }^{8}$ No campo da saúde, iniquidades são desigualdades entre grupos populacionais que, além de sistemáticas e relevantes, são também evitáveis, injustas e desnecessárias (WHITEHEAD, 2000 apud BUSS, 2007).

${ }_{9}^{9}$ Para uma relação completa de unidades Fiocruz no território brasileiro e fora dele, acessar: http://portal.fiocruz.br/ptbr/content/unidades-e-escrit\%C3\%B3rios.

10 No Rio de Janeiro, o campus Fiocruz Mata Atlântica, na região de Jacarepaguá, também se insere, como Manguinhos, no contexto de territórios urbanos densamente povoados e circundados por complexos de comunidades, em que é possível atestar a cronicidade e repetição de questões cujo enfrentamento é dificultado pela imbricação de aspectos únicos, caso a caso. Já o campus IFF, no Flamengo, está cercado por uma população das classes A e B, serviços públicos e privados abundantes e de qualidade, que garantem infraestrutura cuidada, resultando ambiente saudável e seguro; isso torna o Flamengo foco de 
Dimensões constitutivas de tecnologias sociais no campo da saúde: uma proposta de construção e apropriação de conhecimento em territórios vulneráveis

exploração imobiliária permanente, afastando, cada vez mais, as classes C, D e E para bairros menos valorizados ou comunidades favelizadas no entorno destes. 